\title{
PERUBAHAN MAKNA INTERAKSI SOSIAL PADA KEDAI FORE COFEE
}

\author{
Nia Suryani ${ }^{1}$, Fery Mulya Pratama ${ }^{2}$ \\ ${ }^{1}$ Universitas Indraprasta PGRI, Program Studi Arsitektur \\ niasuwardi@gmail.com \\ ${ }^{2}$ Universitas Indraprasta PGRI, Program Studi Arsitektur \\ pratama.ars@gmail.com
}

\begin{abstract}
In the past, the culture of drinking coffee is not just eating a glass of coffee, but the term 'coffee' can be interpreted by discussing, relaxing while listening to music, playing chess, or even just spending leisure time. The 'coffee' activity will certainly be ideal if it is done in a coffee shop, a place where we can interact with others and be interpreted as information centers. With the development of the times, the formation of coffee shops has turned into a more friendly place for all people and attracts the attention of customers. Various innovations were made to be able to compete in the hustle and bustle of this coffee business. One of them is by using the application as a promotional media and store form changes that are far from the formation of coffee shops in general. The observation method shows that the use of the application certainly has an impact on the quality of the social space that is usually present in this coffee shop and forms other social interactions that were not predicted before due to the similarity of interests or goals, but it is increasingly recognized that coffee becomes not essential in the Fore shop, not more than the current drink that is sold in the market today.
\end{abstract}

Keywords: coffee shop, social interaction, aplication

\begin{abstract}
Abstrak. Sejak dulu budaya minum kopi bukan hanya sekedar menyantap segelas kopi, tapi istilah 'ngopi' bisa dimaknai dengan berdiskusi, bersantai sambil mendengarkan musik, bermain catur, atau bahkan sekedar menghabiskan waktu luang. Aktivitas 'ngopi' tentu saja akan lebih ideal jika dilakukan di warung kopi, tempat di mana kita bisa berinteraksi dengan orang lain dan dimaknai sebagai pusat informasi. Semakin berkembangnya zaman, bentukan warung kopi berubah menjadi tempat yang lebih ramah untuk semua kalangan dan menarik perhatian pelanggan. Berbagai inovasi dilakukan untuk bisa bersaing dalam hiruk pikuk bisnis kopi ini. Salah satunya dengan menggunakan aplikasi sebagai media promosi dan perubahan bentuk kedai yang jauh dari bentukan warung kopi pada umumnya. Dengan metode observasi menunjukkan bahwa penggunaan aplikasi tentunya berdampak pada kualitas ruang sosial yang biasanya hadir pada warung kopi ini dan membentuk interaksi sosial lain yang tidak terprediksi sebelumnya karena adanya kesamaan kepentingan atau tujuan, namun semakin disadari bahwa kopi menjadi tak seesensial itu pada kedai Fore, tak lebih dari minuman kekinian yang banyak dijual di pasaran saat ini.
\end{abstract}

Kata Kunci : : kedai kopi, interaksi sosial, aplikasi

\section{PENDAHULUAN}

Tak bisa dipungkiri, bahwa saat ini budaya minum kopi telah menjadi gaya hidup bukan hanya di Indonesia namun juga di dunia. Jika ditilik dari sejarah, kopi ditemukan di daratan Ethiopia pada pergantian abad ke IX sebagai buah yang bisa memberikan tambahan energi dan mampu membuat kita terjaga jika mengkonsumsinya. Sejak saat itu, kopi seolah menjadi salah satu sumber daya alam yang menjadi primadona dan dibudidayakan di setiap negara termasuk Indonesia.

Bahkan, ini yang paling menarik, Ahmad Asma dalam (Fenomena sosial di Warung Kopi, 2015) mengungkapkan pada tahun 1674 para perempuan di London Inggris harus berkoalisi melakukan aksi protes lantaran para suami mereka, para lelaki lebih suka dan lebih banyak menghabiskan waktunya di café (warung kopi) dibanding di rumah. Petisi perempuan menentang kopi pun dikeluarkan. Tidak sampai di situ saja, selanjutnya satu tahun kemudian, pada tahun 1675 Raja Charles II membuat kebijakan untuk menutup seluruh kedai kopi di London. Alasan utama utamanya adalah kedai kopi menjadi tempat untuk melakukan pemufakatan makar.

Sejak dulu budaya minum kopi bukan hanya sekedar menyantap segelas kopi, tapi istilah 'ngopi' bisa dimaknai dengan berdiskusi, bersantai sambil mendengarkan musik, bermain catur, atau 
bahkan sekedar menghabiskan waktu luang. Aktivitas 'ngopi' tentu saja akan lebih ideal jika dilakukan di warung kopi, terdapat kualitas ruang yang mendukung kita bisa berinteraksi dengan orang lain dan dimaknai sebagai pusat informasi. Dari sudut pandang budaya, warung kopi sebagian besar berfungsi sebagai pusat interaksi sosial (meeting point) yang menyediakan sebuah tempat untuk berkumpul, berbicara, bertukar pikiran serta mengutarakan pendapat.

Keberadaan warung kopi yang beroperasi hampir 24 jam hingga larut malam pun berkontribusi pada hidupnya sebuah ruang kota seolah menjadi pelita karena aktivitas dalam warung kopi ini seolah tak pernah berhenti walau bukan aktivitas yang besar dan memicu sebuah keramaian serta memiliki andil dalam membentuk citra dari kota itu sendiri (Lynch, 1960)

Seiring berjalannya waktu dan kemajuan teknologi, warung kopi kian tumbuh menjamur di sekitaran pusat kota atau di jalan-jalan strategis tentunya dengan kualitas ruang yang agak berbeda dengan warung kopi yang kita kenal dulu. Fasad yang menarik perhatian, serta padu padan material lantai, warna dinding, dan pernak pernik lainnya sehingga membuat interior warung kopi tersebut menjadi instagramable. Ditambah dengan adanya $\mathrm{AC}$, akses sumber listrik dan internet membuat kita betah berlama-lama menghabiskan waktu di dalamnya. Warung kopi yang dulu dikenal sebagai pusat informasi dan interaksi sosial sambil menikmati segelas kopi kini lebih dianggap sebagai tempat hits yang bisa memenuhi kebutuhan konsumen akan ruang yang tenang atau hanya sebatas konten media sosial tanpa harus menyantap menu yang memiliki kandungan kopi.

Konten media sosial menjadi komoditas yang sangat berpengaruh pada gaya hidup di masa sekarang. Hal itu terjadi karena pengaruh perkembangan teknologi dan rasa keterikatan keseharian terhadap gadget menjadi sangat lekat. Pengaruh gadget membuat vendor penjual barang dan jasa merubah metode pemasaran mereka yang tadinya menggunakan cara langsung atau tatap muka sekarang menjadi online melibatkan marketplace dan aplikasi. Penggunaan aplikasi dan marketplace tentunya berdampak pada beberapa hal esensial karena interaksi langsung antara penjual dan pembeli, pembeli dan pembeli tentunya tidak terjadi (Burhan,2017).

Salah satu kedai kopi yang melakukan pemasaran produknya menggunakan aplikasi adalah Fore Coffee. Kedai kopi yang mengusung konsep futuristik, spesialti dan sekaligus ecofriendly di saat bersamaan. Fore Coffee adalah sebuah perusahaan start-up bermodel bisnis kedai kopi yang hadir untuk mempersembahkan kopikopi berkualitas tinggi bagi seluruh pencinta kopi di tanah air. Didirikan pada Agustus 2018, Fore Coffee lahir untuk turut meramaikan geliat industri kopi yang kian bergairah terutama sejak beberapa tahun terakhir, dan juga berkontribusi bagi pertumbuhan ekonomi positif di Indonesia. (Yulin Masdakasty,2019 dalam majalah Ottencoffee.co.id).

Fore Coffee sebagai brand kopi juga telah memiliki aplikasi mobile sendiri yang bernama sama, Fore Coffee. Aplikasi mobile yang bisa diunduh di sistem operasi iOS App Store dan Google Playstore ini disebut-sebut sebagai sebuah inovasi di kelasnya, karena mendobrak pembatas antara pelanggan dan kedai kopi. Jika selama ini penikmat kopi umumnya merasa harus ngopi di kafe, atau di warung kopi, kini mereka bisa melakukannya dimana saja dan kapan saja hanya dengan sebuah aplikasi Fore Coffee.

Fore Coffee memiliki lebih dari 50 cabang di Jakarta dan Bandung, salah satunya ada di sekitaran Kampus A Universitas Indraprasta yakni di Tanjung Barat. Kedai Fore Coffee yang ada di Tanjung Barat sangat jauh dari kesan instagramable atau melayani pengunjung dengan tampilan kedai yang nyaman namun penjualan setiap harinya selalu melebihi target. Fenomena ini menggelitik penulis untuk bertanya, bagaimana interaksi sosial yang terbentuk di kedai kopi Fore yang ada di Tanjung Barat dan hal menarik apakah yang membuat kopi ini laku di pasaran?

Penelitian ini dilakukan agar kita sebagai arsitek dapat memahami bagaimana sebuah aplikasi (perkembangan teknologi) dapat mempengaruhi perubahan makna dari interaksi sosial yang terjadi pada sebuah ruang yang sebelumnya menjadi ruang sosial bahkan sebagai pusat informasi. 


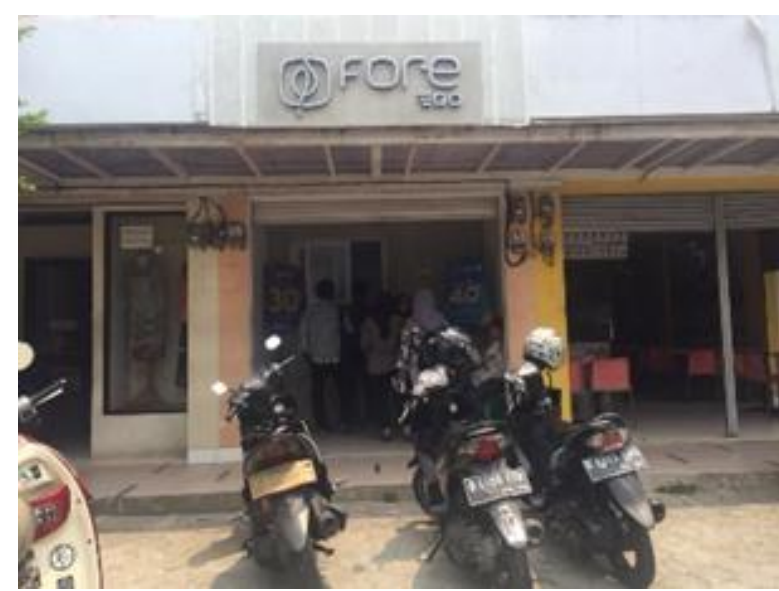

Gambar 1. Suasana Kedai Fore Cofee di Tanjung Barat

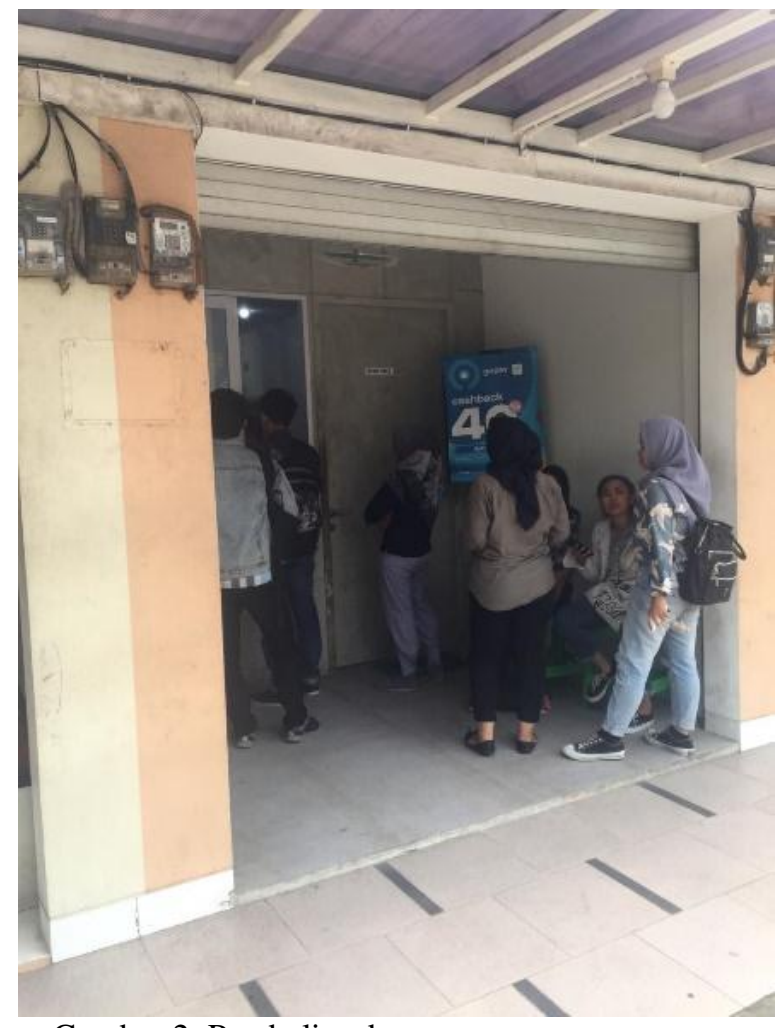

Gambar 2. Pembeli sedang menunggu pesanannya selesai disajikan

\section{METODOLOGI}

Metode yang dilakukan sebagai langkah dalam pencarian data dalam penelitian ini adalah metode kualitatif dengan pengamatan langsung (observasi) dalam kurun waktu 12 hari pada jam operasional kedai Fore pukul 08.00-22.00 yang diuraikan dalam pemetaan sederhana. Pemetaan dilakukan agar peneliti memahami bagaimana setiap pembeli kopi dapat menunjukan kecenderungan perilaku untuk melakukan interaksi di antara mereka (Dawes,2017).
Pemetaan dilakukan secara acak namun terbagi menjadi dua, yakni pembeli pribadi dan pembeli kurir (ojek online).

\section{HASIL DAN PEMBAHASAN}

Sejak dulu, warung kopi memang selalu menjadi pusat informasi dan interaksi sosial. Jika menilik interaksi sosial yang terjadi Ahmad Asma dalam (Fenomena sosial di Warung Kopi, 2015) ini menjelaskan bahwa ada beberapa jenis interaksi sosial yang terjadi di warung kopi yakni Mutualisme dan Sosiality.

Mutualisme adalah interaksi sosial yang saling menguntungkan bagi dua belah pihak. Dalam kegiatan, interaksi di warung kopi semua pihak mendapat keuntungan sesuai dengan peran dan tujuan masingmasing. Pemilik warung mendapat keuntungan dari minuman kopi dan lainnya yang dijual. Pelanggan (pengunjung) mendapat kepuasan menikmati minuman kopi. Sesama pengunjung juga bisa saling berinteraksi, bertukar pendapat, informasi maupun sekedar ngobrol yang membuat masing-masing individu merasa sama-sama senang dan menikmati suasana. Sedangkan Sosiality adalah interaksi sosial yang bersifat kemasyarakatan, bentuk interaksi sosial yang bersumber dari masyarakat yang ada dan berpengaruh pada masyarakat itu sendiri. Minum kopi di warung kopi tercipta dari kesenangan (hobi) masyarakat khususnya para pengopi sebagai subyek pelaku. Para pengunjung warung kopi sebagai individu tidak bisa dilepaskan dari situasi warung dimana ia berada. Berkumpulnya beberapa pengunjung dalam satu tempat yang melakukan hal yang sama (ngopi) menjadikan tercipta situasi minum kopi di warung kopi.

Fenomena, aktivitas dan interaksi yang ada dan berkembang, selanjutnya membentuk kelompok kebersamaan dalam satu tempat 
tersebut. Situasi kebersamaan yang dihadapi para pengopi akan tumbuh dan mengarahkan tingkah laku secara spontan., aktivitas dan interaksi yang terjadi di warung kopi ini memiliki ciri-ciri: tidak terikat satu sama lain, aktornya berinteraksi secara langsung, kurang ada aturan yang terorganisir, interaksinya bersifat spontan, dan adanya kesamaan pandangan-hobby terhadap minat-kebutuhan tertentu.

$\begin{array}{rrr}\text { Menurut } & \text { Ubed A. Syarif dalam } \\ \text { tulisannya di } & \text { kompasiana.com yakni }\end{array}$ Perubahan Sosial: dari Warung Kopi ke Café mengutarakan disadari atau tidak, keberadaan warung-warung kopi sejak dulu, menjadi ruang sosial 'baru', yang terbentuk dari hubungan kebutuhan, konsumsi dan interaksi. Kualitas ruang sebagai tempat bersantai dan membunuh waktu dari warung kopi tercermin dari bentuk kursi "malas" yang disediakan untuk pengunjung. model kursi tersebut seragam digunakan di hampir setiap warung kopi, yaitu berupa kursi (biasanya berbahan plastik), berkaki pendek tidak sampai sebatas lutut orang dewasa tingginya, lebar untuk ukuran dewasa, dudukannya menjorok ke belakang dengan sandaran yang agak jauh ke belakang.Bentukan kursi itu seolah memaksa kita yang duduk untuk "bermalas-malasan", tidak bisa kita menegakkan sandaran kursi atau sekedar duduk tegak mengambil posisi "serius". Kualitas yang seperti inilah yang menambah kenikmatan berlama-lama di warung kopi.

Warung-warung kopi itu di awal tahun 2000 hingga kini menjelma menjadi "Café", ada yang menamakan diri dengan lebih keren "Coffee Shop". Budaya urban menyeret warung kopi pada bentuk modifikasi yang lebih modis dengan sentuhan gaya urban, dengan menu semakin beragam, aneka jenis minuman dan makanan disediakan tentunya bukan hanya yang berbahan dasar kopi, pelayannya pun berseragam, tak sedikit pula pelayan perempuan. Tapi ciri khas "kemalasan" tidak hilang karena "kursi malas" tetap banyak digunakan pada "Coffee Shop" walau dengan bentukan berbeda yakni sofa empuk yang seolah main lama makin menelan tubuh kita agar kita tak cepat-cepat beranjak dari tempat ini. Terkadang kursi malas, AC, dan internet lah yang membuat pengunjung rela mengeluarkan kocek 10 kali lipat lebih besar dibanding harga segelas kopi di warung kopi pinggir jalan. Pengunjung atau pelanggan coffee shop ini juga cukup beragam, dari anak usia remaja hingga dewasa dan orang tua, laki-laki (mayoritas) dan perempuan meski tidak sebanyak laki-laki. Laki-laki-perempuan berpasangan juga sering tampak pada warung kopi bentuk café ni.

Sementara, jika ditilik budaya asli dari warung kopi di kampung-kampung, adalah aktivitas yang hanya dilakukan oleh laki-laki dan hanya menyediakan minuman kopi dan sedikit kue-kue. Jarang sekali ada perempuan berkunjung atau nongkrong di warung kopi di kampung-kampung. Perempuan merasa malu dan tidak patut berkunjung ke warung kopi, jika pun mereka membeli kopi, pasti dibungkus dan dibawa pulang ke rumahnya. Warung kopi seolah benar-benar hadir sebagai ruang milik laki-laki yang tak mudah untuk diinterupsi.

Beragamnya pengunjung dari coffee shop ini semakin memungkinkan banyak interaksi terjadi di tempat ini entah yang terencana ataupun yang tidak. Seringkali coffee shop dijadikan tempat untuk rapat (pertemuan beberapa orang membahas sesuatu), transaksi bisnis, mengerjakan tugas, pacarana atau bahkan sekedar membunuh waktu, hingga membuat konten media sosial yang tak jarang menghasilkan pundi-pundi uang seperti membuat video konten atau endorse.

Semakin menjamurnya warung kopi kekinian atau coffee shop di sekitar kita 
membuat brand kopi saling berinovasi agar bisa bersaing dalam hiruk pikuk bisnis segelas kopi ini. Salah satu inovasi yang paling berdampak signifikan pada animo masyarakat adalah penggunaan aplikasi dari brand kopi tertentu. Aplikasi ini pun sudah dirancang sedemikian rupa sehingga tampak begitu menarik dengan banyak memberikan diskon potongan harga sebagai media promosi sampai dengan menggandeng ojek online sebagai kurir sehingga semakin memudahkan konsumen dalam mendapatkan segelas kopi tanpa harus berpindah atau mengganggu aktivitas rutin dalam keseharian mereka.

Salah satu brand kopi yang telah menggunakan aplikasi adalah Fore Coffee. Brand kopi yang telah melabelkan diri sebagai brand yang peduli dengan lingkungan ini sudah sedikit banyak merubah kebiasaan atau budaya seseorang dalam aktivitas 'ngopi'. Konsumen semakin tertarik tentunya dengan metode pamasaran ini karena mereka tak perlu bermacet-macet ria untuk mendapatkan segelas kopi nikmat, tinggal menunggu sejenak maka menu kopi yang dipesan bisa segera bisa disantap ditambah lagi dengan potongan harga atau diskon yang fantastis tentunya menambah daya tarik Fore Coffee ini. Bayangkan saja, dengan menggandeng dompet digital, sering kali pelanggan hanya membayar 1 rupiah atau bahkan hanya $\mathrm{Rp}$. 4000,- atau bahkan diberikan secara cumacuma atau gratis untuk segelas kopi atau minuman non kopi dengan ukuran besar. Tentu penawaran ini menjadi sangat menggiurkan.

Fore Coffee sudah memiliki banyak store di berbagai penjuru Jakarta, namun sepertinya kedai cabang Tanjung Barat, Ranco ini sedikit berbeda karena memiliki bentukan yang sangat sederhana jika dipadankan dengan bentukan kedai kopi kekinian sehingga seolah cocok dengan tipe pelanggan yang ingin cepat-cepat atau kurir yang mengambil pesanan kopi yang dipesan pelanggan melalui aplikasi tanpa datang ke kedai. Hal itu terlihat dari kedai yang tidak menyiapkan fasilitas atau ruang untuk pelanggan menyantap kopi di kedai tersebut. Kedai terlihat sangat tertutup untuk orang lain yang bukan pekerja dari Fore Coffee ini. Pembagian ruang dari kedai ini hanya terbagi menjadi tempat parkir, area pesan dan tunggu, serta dapur. Pelanggan atau kurir hanya bisa berkomunikasi lewat jendela berukuran $80 \mathrm{~cm}$ x $80 \mathrm{~cm}$ untuk sekedar menyampaikan pesanan (yang sudah tertera di aplikasi) dan mengambil pesanan yang sudah siap untuk dibawa.

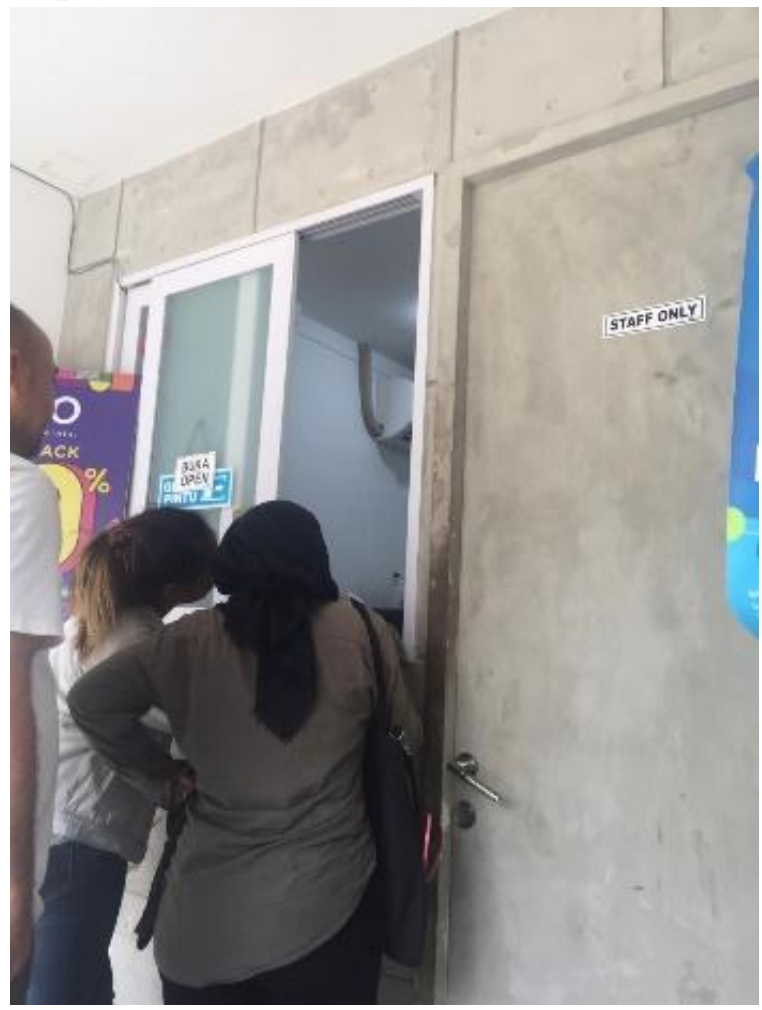

Gambar 3. Jendela atau loket pemesanan tidak seperti kedai kopi kekinian lainnya

Menurut barista dari Fore Coffee, Hampir $80 \%$ dari pelanggan menggunakan aplikasi dompet digital sehingga hampir tidak ada transaksi langsung (cash) di kedai ini. Hal itu seolah membuat Fore Coffee makin mengefektifkan pekerja yang ada di dalam kedai ini. Karena sering kali hanya ada satu orang dalam kedai ini yang memainkan peran sebagai barista sekaligus kasir dan yang memanggil nama pembeli jika 
pesanannya sudah siap. Semua memang seolah dirancang menjadi sangat efektif dan efisien sehingga kedai pun tidak membutuhkan ruang yang besar.

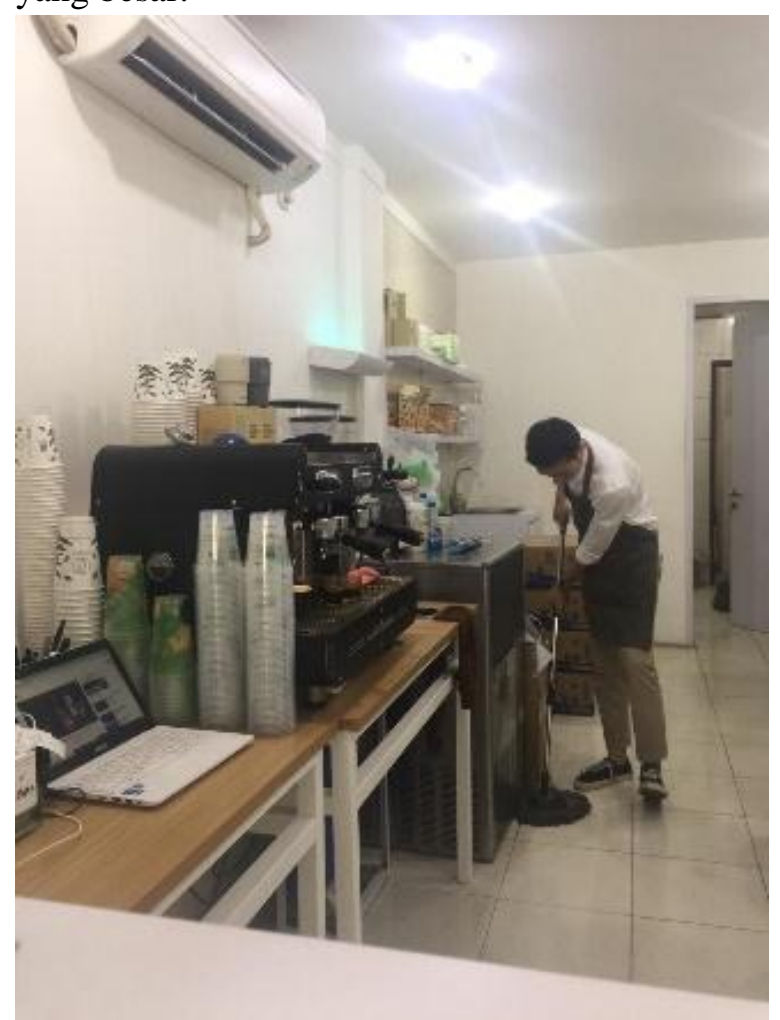

Gambar 4. Suasana di dalam Kedai Fore Cofee

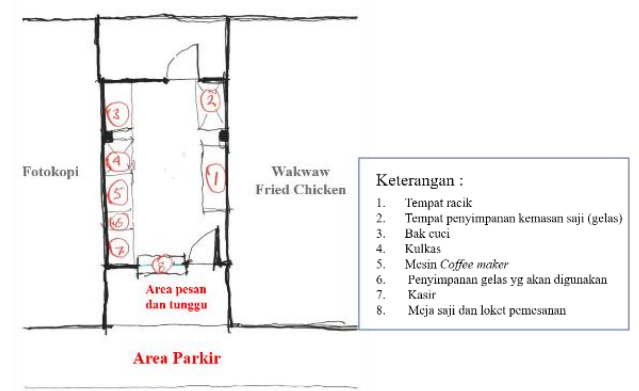

Jalan Raya Nangka

Gambar 5. Pembagian ruang dalam kedai fore cofee

Kualitas ruang yang ada pada kedai Fore Coffee yang ada di Tanjung Barat ini tentunya hampir meniadakan interaksi sosial baik mutualisme yakni interaksi sosial yang saling menguntungkan bagi dua belah pihak. Dalam kegiatan, interaksi di warung kopi semua pihak mendapat keuntungan sesuai dengan peran dan tujuan masing-masing maupun sosiality yakni interaksi sosial yang bersifat kemasyarakatan, bentuk interaksi sosial yang bersumber dari masyarakat yang ada dan berpengaruh pada masyarakat itu sendiri. Tak ada interaksi yang terjadi di kedai ini yang memicu terbentuknya ruang sosial di antara penjual-pembeli dan juga antar sesama pembeli. Semua aktivitas dalam kedai ini memang dirancang untuk serba cepat. Dalam kurun waktu 3-5 menit setiap pesanan sudah bisa siap diambil oleh pembeli.

Namun tanpa disadari terbentuk ruang sosial baru yang hadir karena kedai kopi yang dirancang tidak mengakomodir interaksi sosial antar sesama pembeli dan lebih melibatkan kurir dalam hal ini ojek online. Saat menyampaikan pesanan dari pelanggan hingga pesanan kopi telah siap diambil terdapat waktu tunggu walau hanya sebentar. Waktu tunggu tersebut dimanfaatkan oleh para ojek online ini untuk saling bertukar informasi seputar kemacetan jalan, ramai tidaknya pesanan pelanggan, atau bahkan sekedar bertukar rokok dan korek api. Tentunya interaksi sosial ini bukan sesuatu yang diprediksi dan berlangsung rutin atau berulang dengan aktor yang sama. Interaksi yang terjadi antar ojek online ini tak ada bedanya dengan interaksi yang terjadi di antara mereka di gerai makanan lainnya, sehingga "kopi" ini seolah tak lagi menjadi komoditi spesial lagi, tentunya tidak sebanding dengan kualitas interaksi yang ditawarkan dari sebuah warung kopi sesungguhnya.

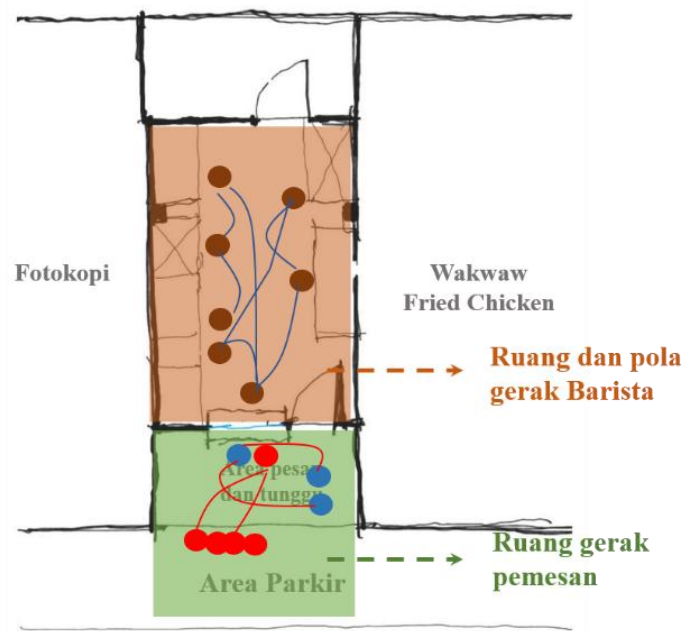

Jalan Raya Nangka 


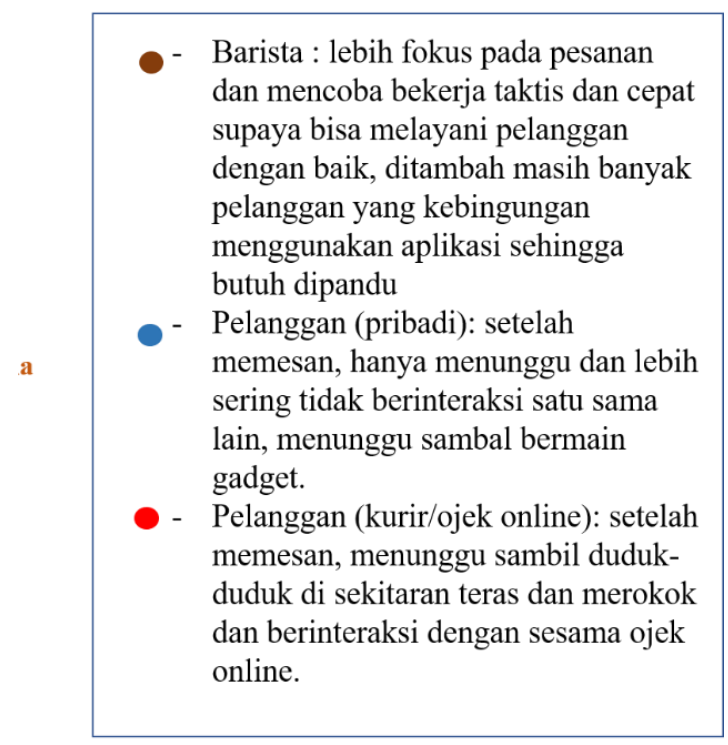

Gambar 6. Pemetaan ruang dan pola gerak barista dan pembeli di kedai Fore Coffe

\section{PENUTUP}

\section{Simpulan}

Warung kopi tetap memiliki daya tarik sebagai sebuah ruang yang mengakomodasi adanya interaksi sosial walaupun sudah berubah mengikuti perkembangan zaman dan teknologi (dengan adanya aplikasi), meskipun interaksi yang terjadi bukanlah sesuatu yang bisa diprediksi. Kedai Fore Coffee yang seolah hampir tidak memiliki potensi terjadi interaksi sosial pun ternyata para ojek online ini seolah membentuk ruang sosial baru di sekitaran tempat parkir yang tidak jauh dari tempat menunggu pesanan. Tentunya interaksi sosial ini bukan sesuatu yang diprediksi dan berlangsung rutin atau berulang dengan aktor yang sama. Interaksi yang terjadi antar ojek online ini tak ada bedanya dengan interaksi yang terjadi di antara mereka di gerai makanan lainnya, sehingga "kopi" ini seolah tak lagi menjadi komoditi spesial lagi, interaksi sosial ini tidak sebanding dengan kualitas interaksi yang ditawarkan dari sebuah warung kopi sesungguhnya.

Peranan ojek online, dompet digital, dan media promosi lain ditambah dengan potongan harga yang menggiurkan membuat Fore Coffee laku di pasaran dan menjadi pesaing kuat bagi brand kopi lainnya.

\section{DAFTAR PUSTAKA}

Burhan, Sathi'ul (2017) Makna Interaksi Sosial di Ruang Publik (Studi pada Pengguna Media Sosial di Warung Kopi Gapuro). , University of Muhammadiyah Malang

Dawes, Michael J.2017. Christopher Alexander's A Pattern Language : Analysing, mapping, classifying the critical response. City, Territory and ArchitectureAn interdisciplinary debate on project perspectives

Lynch, K. (1960). The Image of The City. MIT Press. Madnipour, A. (1996). Design of Urban Space, An Inquiri into a SocioSpatial Process. New York: John Wiley \& Sons.

https://www.kompasiana.com/ubedas y/54f374ed745513982b6c7730/perubahansosial-dari-warung-kopi-ke-cafe

https://pontianakopi.wordpress.com/2 015/05/18/fenomena-sosial-di-warung-kopi3/

https://majalah.ottencoffee.co.id/forecoffee-next-generation-coffee-shop/ 